\title{
Comparative genetic structure of two co- occurring tree species, Mac/ura pomifera (Moraceae) and Gleditsia triacanthos (Leguminosae)
}

\author{
ANDREW SCHNABEL, * ROGER H. LAUSHMAN $\dagger$ \& J. L. HAMRICK $\ddagger$ \\ *Department of Genetics, University of Georgia, Athens, Georgia 30602, USA, †Department of Biology, Oberlin College, \\ Oberlin, Otio 44074, USA and †Departments of Botany and Genetics, University of Georgia, Athens,
}

Georgia 30502, USA

\begin{abstract}
Maclura pomifera, an autotetraploid, and Gleditsia triacanthos, a diploid, are ecologically similar dioecious tree species that often co-occur in early successional habitats throughout the mid-western United States. We studied levels of genetic diversity and patterns of genetic structure for four polymorphic enzyme loci of $M$. pomifera and 16 polymorphic enzyme loci of $G$. triacanthos from a single population in eastern Kansas. Levels of expected heterozygosity were high for both species, averaging 0.725 for $M$. pomifera and 0.366 for $G$. triacanthos. Although genotypes for nearly all $G$. triacanthos loci were in Hardy-Weinberg frequencies, three of four $M$. pomifera loci deviated from equilibrium expectations. Two aspects of genetic structure were explored. First, the extent of clonal growth was estimated by comparing genotypes of stems within $50 \mathrm{G}$. triacanthos and $32 \mathrm{M}$. pomifera clumps. The great majority of clumps contained more than one genotype, and in many clumps, all stems were genetically unique. Secondly, as revealed by spatial autocorrelation analyses, genetic substructure was very local for both species, with significant positive autocorrelation occurring only within clumps of individuals or among near neighbours. We argue that this pattern of spatial structure for both species results from extremely local seed dispersal and establishment of individuals from the same multiseeded fruit.
\end{abstract}

Keywords: autotetraploidy, genetic structure, Gleditsia tricanthos, Maclura pomifera, spatial autocorrelation.

\section{Introduction}

Although the majority of studies of genetic structure in plants focus on patterns of variation among wellseparated populations, genetic structure can be, and often is, manifested at scales of only a few metres (e.g. Hamrick \& Holden, 1979; Turkington \& Harper, 1979; Schoen \& Latta, 1989). Investigations of genetic substructure within populations have generally fallen into two categories: those that investigate the possibility of microgeographic adaptation, and those that investigate patterns of mating and gene movement. These two categories are, of course, not mutually exclusive, because selection and patterns of gene movement can interact in complex ways either to increase or decrease structure (Jain \& Bradshaw, 1966; Sokal et al., 1989; Epperson, 1990a, b). A welldeveloped theory also indicates that localized gene movement alone can cause pronounced spatial sub- structure through the action of increased genetic drift and inbreeding (Wright, 1943; Rohlf \& Schnell, 1971; Turner et al., 1982; Epperson, 1990a). An immediate consequence of this theory is that species with similar reproductive biology and dispersal patterns should, when growing sympatrically, exhibit similar patterns of spatial structure (Loveless \& Hamrick, 1984). We test this expectation by describing spatial genetic structure in a single population of Gleditsia triacanthos and Maclura pomifera from eastern Kansas.

The list of ecological traits shared by $M$. pomifera and $G$. triacanthos is extensive. Both are dioecious trees that commonly colonize pastures and old fields and are often found together in those habitats throughout the mid-western region of the United States (Smith \& Perino, 1981; Schnabel \& Laushman, personal observations). Flowers of $M$. pomifera and $G$. triacanthos emerge in May or early June, either after or at the same time as the leaves. Male trees of both 
species flower yearly, whereas flower and fruit production in females is highly variable from year to year (Schnabel \& Laushman, unpublished data). Both species produce heavy, multiseeded fruits, with the number of seeds per fruit reaching 30 for $G$. triacanthos (Gordon, 1966; Mathwig, 1971) and several hundred for $M$. pomifera (Smith \& Perino, 1981). Seed dispersal in both species is highly localized, most of the fruits falling directly beneath the parent tree (Schnabel \& Laushman, personal observations). Secondary dispersers include horses, cattle, and deer (all of which most likely account for the rapid spread of both species into open fields), as well as a variety of small mammals (Bugbee \& Riegel, 1945; Dice, 1945; Peattie, 1953; Fowells, 1965).

The majot ecological difference between the two species is in their pollination mechanisms; $M$. pomifera is wind-pollinated, whereas $G$. triacanthos is pollinated by a variety of insects, including bees, moths, and butterflies (Schnabel, 1988). Because of this difference, one might expect gene flow via pollen to be more localized in $G$. triacanthos than in $M$. pomifera, thereby increasing the probability that spatial genetic structure will develop due to isolation by distance. Schnabel (1988) has shown, however, that 15-50 per cent of the effective pollinations in three $G$. triacanthos sites are by pollen originating outside the sites. These values are comparable to estimates of pollen migration rates for wind-pollinated species (Friedman \& Adams, 1985; Nagasaka \& Szmidt, 1985; Harju \& Muona, 1989]. More specifically for the site discussed in this paper, nearly 50 per cent of the sampled progeny were sired by individuals not within the site, and no association was found between an individual's location in the site and the proportion of its ovules fertilized by immigrant pollen (Schnabel, 1988). Therefore, at least over the spatial scale discussed in this paper, we believe that differences in pollination mechanisms between $M$. pomifera and $G$. triacanthos do not indicate significant differences in patterns and levels of effective pollen movement.

\section{Materials and methods}

\section{Description of study site}

The site for our study (hereafter referred to as WCS) is located on the West Campus of the University of Kansas in Lawrence and is dominated by $M$. pomifera and $G$. triacanthos. All $M$. pomifera trees in this population are likely to have derived from an old hedgerow growing along the north-western edge of the site. The original source of $G$. triacanthos appears to be a large stand located on a hill behind the old $M$. pomifera hedgerow. At present, the area of the site is 2-3 hectares.

The physical locations of individual stems within this area were determined by mapping them onto a grid of $10 \mathrm{~m}^{2}$ quadrats. Because of the presence of an excessively large number of $G$. triacanthos stems, only those within a $60 \times 130 \mathrm{~m}^{2}$ central portion of the site were mapped. The smaller number of $M$. pomifera stems allowed us to map the entire site. All mapped stems were also scored for sexual expression: male, female, or neuter.

The most distinctive characteristic of the spatial distribution of $M$. pomifera and $G$. triacanthos in this site is the prevalence of clumped growth. Here we define a clump as a group of two or more stems that are either touching at their bases or are growing so close together that they could not be accurately assigned separate spatial coordinates. Over 54 per cent of the $M$. pomifera stems $(113$ or 207$)$ and 58 per cent of the mapped G. triacanthos stems ( 150 or 258) at WCS are growing in clumps. These clumps range in size from 2-9 stems, averaging $( \pm$ s.d. $3.53 \pm 1.63$ stems per $M$. pomifera clump and $3.00 \pm 1.43$ stems per $G$. triacanthos clump.

The abiliry of individuals of both species to resprout multiple stems after injury of the primary stem suggists that many clumps may be single individuals (Fowells, 1965; Smith \& Perino, 1981). It is common in this population, however, for dispersers to sit directly at the base of trees while extracting seeds from fruits (A. Schnabel \& R. H. Laushman, personal observations). Germination of seeds that escape predation could thus lead to clumps composed of several genetically unique individuals. More importantly, if fruits are frequently dispersed to the base of their maternal parent, individuals within clumps will be closely related, and we would expect to find significant spatial genetic structure over very short distances. If, on the other hand, fruits are regularly carried to the bases of neighbouring trees or even further, we would expect to observe either weak genetic substructuring over a slightly larger scale or no structure at all.

\section{Electrophoresis}

Mature leaf tissue for use in horizontal starch gel electrophoresis was collected from all mapped stems. Each $G$. triacanthos stem was scored for 12 enzyme systems (16 loci): acid phosphatase $(A c p)$, diaphorase (Dia 2), fluorescent esterase ( $\mathrm{Fe} 2, \mathrm{Fe} 3$ ), glutamate oxaloacetate transaminase (Got2), leucine aminopeptidase (Lap I, Lap2), malate dehydrogenase (Mdh), malic enzyme $(\mathrm{Me})$, 6-phosphogluconate dehydrogenase (6Pgd2\}, phosphoglucoisomerase (Pgil, Pgi2), 
phosphoglucomutase (Pgm1, Pgm2), shikimate dehydrogenase ( $S k d h)$, triosephosphate isomerase (Tpil). Four enzyme loci, which have recently been shown to undergo tetrasomic inheritance (Laushman et al., 1990), were scored for each $M$. pomifera stem: Lap1, Pgi2, Tpi1, Tpi2. A summary of the gel and electrode buffers used to resolve these enzyme systems is given in Table 1. Further details of electrophoretic protocols for $G$. triacanthos are presented elsewhere (Schnabel, 1988; Schnabel \& Hamrick, 1990).

\section{Data analysis}

We investigated the extent of clonal growth for each species by comparing genotypes of stems within the 50 $G$. triacanthos and $32 \mathrm{M}$. pomifera clumps found in the mapped areas. Clumps of stems with identical multilocus genotypes were considered to represent ramets of a single individual and only one of those genetically identical stems was used in subsequent analyses. The presence of both male and female stems within some clumps helped to corroborate the results of these comparisons.

As the number of loci used in this analysis was four times greater for $G$. triacanthos than for $M$. pomifera, it might be expected that our power to distinguish between genets and ramets is much greater in $G$. triacanthos. This would cause us mistakenly to reduce the number of $M$. pomifera stems used in all subsequent analyses and possibly could bias our results. Such an intuitive argument is misleading, however, because the tetrasomic inheritance pattern exhibited by

Table 1 Electrode and gel buffers used to resolve three enzyme systems in Maclura pomifera and 12 in Gleditsia triacanthos. Buffer system 1 is from Mitton et al. (1977); Buffer systems 2, 3, and 4 are from Soltis et al. (1983)

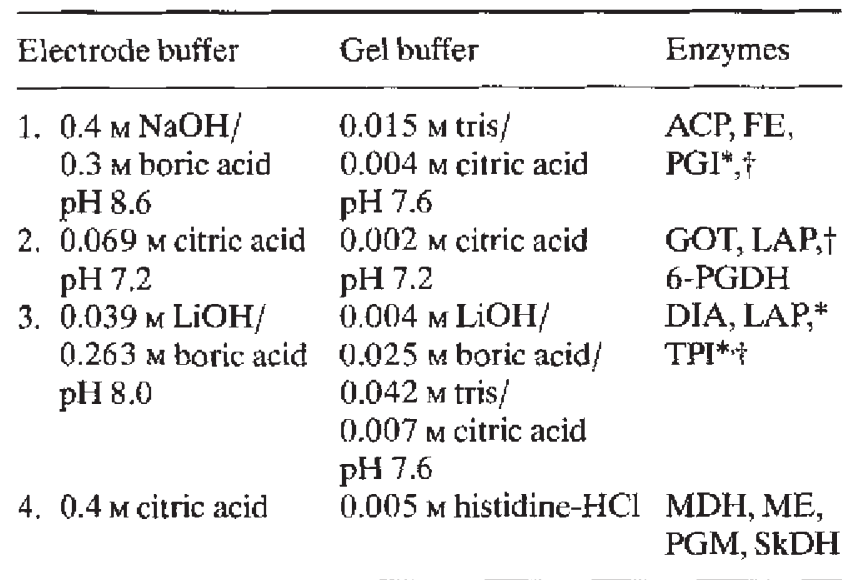

\footnotetext{
* Maclura pomifera.
}

$\uparrow$ Gleditsia triacanthos. each $M$. pomifera locus greatly expands the number of possible four-locus genotypes. For example, the greatest expected four-locus genotype frequency in our population is only 0.0034 (this expectation is based on an assumption of Hardy-Weinberg equilibrium at each locus, and no linkage among loci), which indicates that we expect to find that genotype only about once in our population of $207 \mathrm{M}$. pomifera stems. In fact, exclusive of identical genotypes within clumps, we found only six pairs of identical genotypes and one group of three identical genotypes in the population.

As we have argued above, however, the individuals within clumps may be related, and this would increase the chance of their having identical genotypes. To investigate this possible source of bias, we calculated the frequency of identical four-locus genotypes within open-pollinated progeny arrays (most likely half sibs) and within full-sib arrays from controlled crosses (Laushman et al., 1990). Of the 12 open-pollinated fruits ( 24 seeds analysed per fruit), only two had single pairs of seeds with identical genotypes. Even within full-sib progeny arrays, the frequency of the most common four-locus genotypes never surpassed 10 per cent. All of these lines of evidence convince us that individuals within clumps of $M$. pomifera stems are very unlikely to have identical genotypes unless they are ramets of the same clone.

Deviations of genotype frequencies from equilibrium expectations were determined for loci of both species by chi-square analyses. Approximate chisquare tests for the four $M$. pomifera loci were conducted by excluding all genotypic classes with expected values less than one and grouping certain genotypes to reduce the frequency of classes with expected numbers less than five (Zar, 1974). For $G$. triacanthos, chisquare values were calculated from fixation indices using the formula $\chi^{2}=F^{2} N(k-1)$, where $F$ is the fixation index, $N$ is the sample size, and $k$ is the number of alleles (Li \& Horvitz, 1953).

We used spatial autocorrelation (SA) analyses to test for spatial genetic structure within the $G$. triacanthos and $M$. pomifera populations. The degree of spatial autocorrelation was quantified by calculating a coefficient of SA (Moran's $I$ ), using formulas for ranked data (Sokal \& Oden, 1978). Following the method of Dewey \& Heywood (1988), each of the alleles at the four $M$. pomifera and $16 G$. triacantios loci was analysed separately. For $G$. triacanthos alleles, individuals not possessing a certain allele were given a rank of 0 , whereas individuals with one or two copies of the allele (heterozygotes or homozygotes) were given ranks of 1 or 2 , respectively. Because $M$. pomifera individuals carry four alleles at each locus, the corresponding rankings were $0,1,2,3$ and 4 . We excluded one allele 
at each diallelic locus as well as all alleles that were present in fewer than three individuals in the population, because those alleles provided no additional information concerning spatial structure. At loci with greater than two alleles, certain pairs of alleles appeared not to be independent of one another, and only one of those alleles was used. 'The expected value for $I$, given $n$ pairs of individuals, is $(n-1)^{-1}$, and significant deviation from this value can be assessed using standard normal deviates (Sokal \& Oden, 1978).

Spatial information for the calculation of $I$ came from matrices of binary weights (i.e. 0 or 1 ), which were generated based on the specific hypothesis of structure to be tested. As described above, we expected spatial structure to be strongest over short distances, either within clumps or among nearest neighbours. Therefore, first we investigated SA solely within clumps by assigning weights of 1 to all possible pairs of individuals separated by $1 \mathrm{~m}$ or less, and 0 to all other pairs. In a second separate analysis, we assigned weightings of 1 to all pairs of individuals joined by a Gabrielconnecting algorithm (Gabriel \& Sokal, 1969), which generally joins each individual with several nearest neighbours (Sokal \& Oden, 1978), and 0 to all other pairs.

A general picture of the spatial scale of genetic substructuring was obtained by constructing plots of the change in SA with distance (correlograms) (Sokal \& Oden, 1978). For each species we calculated Moran's $I$ for all pairs of individuals within several distance intervals. The intervals were not identical for the two species, because we attempted to select intervals that gave similar sample sizes both among intervals and between species. For $M$, pomifera, the intervals were $0-10,10-16$ and $16-22 \mathrm{~m}$, with an average sample size (number of pairs per interval) of 585 . The corresponding intervals for $G$. triacanthos were $0-4,4-7$, 7-10, 10-12 and 12-14 $\mathrm{m}$, with an average sample size of 577 . Statistical significance of the correlograms was assessed using the Bonferroni method suggested by Oden (1984).

\section{Results}

Little of the clumped distribution of stems at WCS could be attributed to clonal growth. Of the $32 \mathrm{M}$. pomifera clumps, 23 ( 72 per cent) contained more than one genotype, and in 13 of those, all stems were genetically unique. Similarly, 48 of $50 \mathrm{G}$. triacanthos clumps (96 per cent) included more than one individual, with 44 of those clumps being composed soley of genetically unique stems. The mean numbers of genetically distinct individuals ( \pm s.d.) per clump were $2.81 \pm 1.80$ and $2.84 \pm 1.43$ for $M$. pomifera and $G$. triacanthos, respectively. The total number of trees used in all subsequent analyses was 184 (90 in chumps) for $M$. pomifera and 250 (142 in clumps) for $G$. triacanthos.

On the whole, both species maintain high levels of genetic variation at the loci examined. Levels of heterozygosity at the four $M$. pomifera loci were very high $\left(\bar{H}_{\mathrm{E}}=0.725\right.$; Table 2$)$, and 56 per cent of the individuals carried three or four different alleles for at least one locus. For each locus, observed heterozygosity was slightly less than expected for a population in genetic equilibrium. Genotype frequencies at the Tpi1 locus were very close to expected frequencies $\left(\chi^{2}=1.45\right.$, d.f. $=2, P>0.25)$, but significant departures from equilibrium were found for the Lapl locus $\left(\chi^{2}=52.68\right.$, d.f. $\left.=9, \quad{ }^{*} P<0.001\right)$, the Pgi 2 locus $\left(\chi^{2}=46.23\right.$, d.f. $=21, P<0.005)$, and the Tpiz locus $\left(\chi^{2}=15.58\right.$, d.f. $=7, P<0.05$ ).

More than two alleles were observed at 12 of $16 G$. triacanthos loci, and levels of expected heterozygosity were generally high $\left(\tilde{H}_{\mathrm{E}}=0.366\right.$; Table 3$)$. For the most part, genotype frequencies did not deviate from Hardy-Weinberg expectations. The exceptions were $A c p$, which had a significant excess of heterozygotes, and Pgil and Pgm1, both of which showed heterozygote deficiencies.

Table 2 Allele frequencies, observed heterozygosity $\left(H_{0}\right)$ and expected heterozygosity $\left(H_{\mathrm{E}}\right)$ at four loci for $M$. pomifera. Calculations of $H_{\mathrm{E}}$ were based on an assumption of tetrasomic inheritance

\begin{tabular}{|c|c|c|c|c|c|c|c|c|c|}
\hline \multirow[b]{2}{*}{ Locus } & \multicolumn{7}{|c|}{ Allele frequencies } & \multirow[b]{2}{*}{$H_{\mathrm{o}}$} & \multirow[b]{2}{*}{$H_{\mathrm{E}}$} \\
\hline & 1 & 2 & 3 & 4 & 5 & 6 & 7 & & \\
\hline LapI & 0.075 & 0.232 & 0.664 & 0.012 & 0.013 & 0.003 & - & 0.774 & 0.803 \\
\hline$P g i 2$ & 0.012 & 0.171 & 0.150 & 0.088 & 0.397 & 0.083 & 0.099 & 0.956 & 0.974 \\
\hline Tpil & 0.936 & 0.064 & - & - & - & - & - & 0.226 & 0.234 \\
\hline Tpi2 & 0.001 & 0.024 & 0.488 & 0.485 & 0.001 & - & - & 0.833 & 0.888 \\
\hline Mean & - & - & - & - & - & - & - & 0.697 & 0.725 \\
\hline
\end{tabular}


Table 3 Allele frequencies, observed heterozygosity $\left(H_{0}\right)$, and Hardy-Weinberg expected heterozygosity $\left(H_{\mathrm{E}}\right)$ at 16 polymorphic loci for $G$. triacanthos. Fixation indices $(F)$ estimate deviations from Hardy-Weinberg genotype frequencies

\begin{tabular}{llllllllll}
\hline & \multicolumn{7}{c}{ Allele frequencies } \\
\cline { 2 - 7 } Locus & 1 & 2 & 3 & 4 & 5 & $H_{\mathrm{o}}$ & \multicolumn{2}{l}{$H_{\mathrm{E}}$} & \multicolumn{1}{l}{$F$} \\
\hline Acp & 0.581 & 0.284 & 0.129 & 0.006 & - & 0.660 & 0.565 & $-0.165^{*}$ \\
Dia2 & 0.094 & 0.906 & - & - & - & 0.156 & 0.170 & 0.086 \\
Fe2 & 0.120 & 0.814 & 0.002 & 0.064 & - & 0.312 & 0.319 & 0.024 \\
Fe3 & 0.020 & 0.542 & 0.020 & 0.418 & - & 0.532 & 0.531 & 0.000 \\
Got2 & 0.002 & 0.880 & 0.010 & 0.102 & 0.006 & 0.212 & 0.215 & 0.016 \\
LapI & 0.286 & 0.252 & 0.032 & 0.180 & 0.250 & 0.716 & 0.759 & 0.058 \\
Lap2 & 0.876 & 0.036 & 0.088 & - & - & 0.248 & 0.224 & -0.107 \\
Mdh & 0.308 & 0.538 & 0.154 & - & - & 0.612 & 0.592 & -0.032 \\
Me & 0.046 & 0.954 & - & - & - & 0.092 & 0.088 & -0.046 \\
6Pgd2 & 0.616 & 0.378 & 0.006 & - & - & 0.504 & 0.478 & -0.053 \\
Pgil & 0.297 & 0.315 & 0.388 & - & - & 0.560 & 0.662 & $0.156^{* *}$ \\
Pgi2 & 0.322 & 0.678 & - & - & - & 0.396 & 0.437 & 0.095 \\
Pgm1 & 0.004 & 0.956 & 0.040 & - & - & 0.072 & 0.084 & $0.149^{*}$ \\
Pgm2 & 0.050 & 0.012 & 0.900 & 0.036 & 0.002 & 0.186 & 0.186 & -0.030 \\
Skdh & 0.888 & 0.040 & 0.072 & - & - & 0.212 & 0.205 & -0.034 \\
Tpi1 & 0.212 & 0.788 & - & - & - & 0.354 & 0.334 & -0.051 \\
Mean & - & - & - & - & - & 0.364 & 0.366 & 0.004 \\
\hline
\end{tabular}

* $P<0.05$; ** $P<0.01$.

For both species, the large majority of alleles were positively autocorrelated, and more alleles had significant values of $I$ than would be expected by chance alone (Tables 4 and 5). On the whole, very little structure was evident for $M$. pomifera. For the within-clump and near-neighbour analyses, only two and three of the 14 alleles at the four loci were significantly positively autocorrelated. Despite the increased statistical power of the near-neighbour analysis, the greatest level of spatial autocorrelation for $G$. triacanthos was found within clumps, where Moran's $I$ was significantly greater than zero for 12 of 33 alleles. Among near neighbours, eight $G$. triacanthos alleles were significantly autocorrelated. For $M$. pomifera, none of the alleles showing significant SA within clumps were also significant among near neighbours, whereas six $G$. triacanthos alleles were significantly autocorrelated in both analyses. There were no significant differences between species in the levels of spatial autocorrelation (chi-square tests) either within clumps or among near neighbours.

The correlograms (not shown) wete in general agreement with the results from the within-clump and near-neighbour analyses in that significant autocorrelation was mostly limited to the smallest distance intervals. For $M$. pomifera, three alleles were significantly autocorrelated in the first interval $(0-10 \mathrm{~m})$, none were significant in the second interval $(10-16 \mathrm{~m})$, and one was significant in the third interval (16-22 m). For $G$. triacanthos, significant positive autocorrelation was found for 13 alleles within the first interval $(0-4 \mathrm{~m})$, but for no more than three alleles within any of the four remaining intervals.

\section{Discussion}

The high levels of genetic diversity observed at the loci used in this study are representative of those found for the same loci throughout the ranges of $M$. pomifera and G. triacanthos (Schnabel \& A. Hamrick, 1990; A. Schnabel \& R. H. Laushman, unpublished data), and are also consistent with expectations for highly outcrossing, woody species (Hamrick et al., 1979; Hamrick \& Godt, 1990\}. Moreover, the especially high levels of genetic diversity observed in $M$. pomifera are consistent with theoretical expectations for autopolyploids, which because they can carry more than two alleles at a single locus, should harbor greater amounts of genetic diversity within populations, as well as a greater diversity of enzymes within individuals (enzyme multiplicity), relative to diploid species (Haldane, 1930; Levin, 1983; Stebbins, 1980).

These expectations now have considerable support from studies of allozyme diversity in polyploid species. Hamrick et al. (1979), for instance, found a strong positive relationship between chromosome number 
and three measures of allozyme diversity (polymorphism, number of alleles per locus, and heterozygosity), indicating that taxa derived from an ancient polyploid event may retain high residual levels of

Table 4 Moran's coefficient of spatial autocorrelation for 14 $M$. pomifera alleles, based on pairings either within clumps ( $I_{\mathrm{WC}}$ ) or among near neighbours $\left\langle I_{\mathrm{NN}}\right\}$

\begin{tabular}{lcc}
\hline Allele & \multicolumn{1}{c}{$I_{\mathrm{WC}}{ }^{\dagger}$} & \multicolumn{1}{l}{$I_{\mathrm{NN}}{ }^{\dagger}$} \\
\hline Lap1-1 & 0.143 & $0.142^{*}$ \\
Lap1-2 & 0.043 & 0.077 \\
Lap1-3 & 0.011 & 0.088 \\
Lap1-4 & 0.051 & 0.062 \\
Lap1-5 & -0.055 & 0.011 \\
Pgi2-1 & -0.009 & -0.001 \\
Pgi2-2 & $0.193^{*}$ & -0.013 \\
Pgi2-4 & 0.110 & -0.001 \\
Pgi2-5 & 0.047 & $0.130^{*}$ \\
Pgi2-6 & 0.090 & -0.033 \\
Pgi2-7 & 0.096 & 0.018 \\
Tpil-2 & -0.033 & 0.019 \\
Tpi2-2 & 0.067 & $0.169^{* *}$ \\
Tpi2-4 & $0.172^{*}$ & -0.013 \\
\hline
\end{tabular}

${ }^{*} P<0.05 ; * * P<0.01$.

† Mean distance \pm s.d. between 138 pairs $=0.03 \pm 0.10 \mathrm{~m}$; s.d. of $I_{W C}=0.084$.

${ }_{7}^{2}$ Mean distance \pm s.d. between 298 pairs $=7.93 \pm 8.45 \mathrm{~m}$; s.d. of $J_{\mathrm{NN}}=0.057$. genetic diversity even though they may currently behave as diploids. Recent direct comparisons of autotetraploids and their diploid progenitors have strengthened that relationship by consistently finding greater overall genetic diversity in tetraploid populations (Bayer, 1989; Ness et al., 1989; Soltis \& Soltis, 1989; Wolf et al., 1990). Furthermore, high frequencies of individuals carrying three or four different alleles at one or more loci in autotetraploid populations have been documented for Tolmiea menziesii (Soltis \& Soltis, 1989) and Heuchera grossularifolia (Wolf et al., 1990 ).

In agreement with those earlier studies, heterozygosity and enzyme multiplicity at the $M$. pomifera loci were particularly high. Because we have been unable to locate any diploid $M$. pomifera populations, a direct comparison of heterozygosity between ploidy levels is impossible, but observed heterozygosities for all four loci were much greater than would be expected for a diploid population with equivalent allele frequencies and Hardy-Weinberg genotypic frequencies. Moreover, heterozygosities for $P g i 2$ and $T p i 2$ were higher than the theoretical maximum (i.e. all alleles in equal frequency for each locus) for a diploid population in Hardy-Weinberg equilibrium.

More readily testable from our data is the theoretical prediction that, in autotetraploid populations, equilibrium genotype frequencies are attained asymptotically over several generations and not in a single

Table 5 Moran's coefficient of spatial autocorrelation for 33 G. triacanthos alleles, based on pairings either within clumps $\left(I_{\mathrm{WC}}\right)$ or among near neighbours $\left(I_{\mathrm{NN}}\right)$

\begin{tabular}{|c|c|c|c|c|c|}
\hline Allele & $I_{\mathrm{WC}^{\dagger}}^{\dagger}$ & $I_{\mathrm{NN}}+$ & Allele & $I_{\mathrm{WC}}$ & $I_{\mathrm{N} X}$ \\
\hline ACp-I & 0.098 & 0.043 & Lap 2-4 & -0.032 & 0.043 \\
\hline$A c p-2$ & $0.194^{* * *}$ & $0.100^{*}$ & $M d h-2$ & 0.113 & 0.089 \\
\hline$A c p-4$ & -0.005 & -0.010 & $M d h-4$ & $0.195^{* *}$ & $0.142^{* *}$ \\
\hline Dia2-2 & $0.124^{*}$ & 0.017 & $M e-2$ & $0.127^{*}$ & 0.063 \\
\hline $\mathrm{Fe} 2-\mathrm{I}$ & $0.127^{*}$ & $0.122^{*}$ & $6 P g d 2-1$ & 0.011 & 0.051 \\
\hline $\mathrm{Fe} 2-4$ & $0.133^{*}$ & 0.064 & $6 P g d 2-3$ & $0.361^{\text {***kk }}$ & $0.217^{* * *}$ \\
\hline $\mathrm{Fe} 3-\mathrm{I}$ & -0.034 & -0.046 & Pgil-1 & $0.183^{* *}$ & $0.171^{* * *}$ \\
\hline $\mathrm{Fe} 3-2$ & 0.096 & 0.055 & Pgil-3 & 0.048 & 0.059 \\
\hline $\mathrm{Fe} 3-3$ & 0.103 & 0.013 & Pgi2-3 & -0.028 & -0.033 \\
\hline Got $2-2$ & $0.210^{\text {***}}$ & 0.072 & Pgml-2 & $0.231^{\text {*** }}$ & 0.078 \\
\hline Got $2-3$ & -0.010 & -0.016 & $\operatorname{Pgm} 2-1$ & 0.006 & 0.015 \\
\hline Got2-5 & 0.003 & -0.013 & $\operatorname{Pgm} 2-3$ & -0.012 & 0.021 \\
\hline LapI-I & 0.037 & 0.053 & $P g m 2-4$ & $0.203^{* *}$ & $0.141^{* *}$ \\
\hline Lap1-3 & 0.016 & 0.042 & Skdh-3 & 0.066 & 0.034 \\
\hline Lapl-4 & $0.199^{* *}$ & 0.069 & Skdh-4 & 0.030 & $0.126^{*}$ \\
\hline Lap1-5 & 0.049 & $0.109^{*}$ & Tpil-2 & -0.035 & 0.033 \\
\hline Lap 2-2 & 0.002 & 0.084 & & & \\
\hline
\end{tabular}

$* P<0.05 ; * * P<0.01 ; * * * P<0.001$.

$¥$ Mean distance \pm s.d. between 233 pairs $=0.23 \pm 0.26 \mathrm{~m}$; s.d. of $I_{\mathrm{WC}}=0.065$.

$\ddagger$ Mean distance \pm s.d. between 368 pairs $=4.27 \pm 4.64 \mathrm{~m}$; s.d. of $J_{\mathrm{NN}}=0.052$. 
generation as is true for randomly mating, diploid populations $(\mathrm{Li}, 1976)$. As $\langle\mathrm{i})$ the time to first reproduction in $M$. pomifera is about 10 years (Smith \& Perino, 1981); (ii) the West Campus population is no more than 30-40 years of age; and (iii) all $M$. pomifera trees within it descend from a small planted hedgerow that was probably not in genetic equilibrium, it is not surprising that genotype frequencies at three of four $M$. pomifera loci deviated significantly from equilibrium expectations. The much smaller proportion of $G$. triacanthos loci that deviated from Hardy-Weinberg equilibrium can be attributed to its lower ploidy level and the fact that all G. triacanthos at WCS derive from a much larger natural population. In general, populations of $G$. triacanthos throughout its range show little deviation from Hardy-Weinberg frequencies at allozyme loci (Schnabel \& Hamrick, 1990).

In this study, we found that several alleles of both species were not randomly distributed within the site, but instead showed significant spatial autocorrelation over short distances. For three reasons, we feel that this genetic structure is being generated by spatially limited seed dispersal and not by spatially varying selection. First, the degree and scale of substructure for $G$. triacanthos at WCS is similar to that observed in two other Kansas populations (Schnabel \& Hamrick, 1990). Such consistency across several populations is typically interpreted as evidence that spatial genetic structure is being caused by short-distance gene dispersal (Epperson \& Clegg, 1986; Schoen \& Latta, 1989). Secondly, in contrast to other studies that implicate natural selection as the cause of non-random genetic patterns (e.g. Hamrick \& Holden 1979; Turkington \& Harper, 1979), the small area over which we sampled had no clear microhabitat heterogeneity. Thirdly, unlike pollen dispersal, seed dispersal for both $M$. pomifera and G. triacanthos is extremely localized, with many of the fruits being carried to the base of their maternal parent, or to the base of a neighbouring tree, before seeds are extracted. That over half of the individuals of both species are found in single- or mixed-species clumps supports those observations. Furthermore, casual observations indicate that ateas directly surrounding the bases of these clumps provide especially good microsities for seed germination; few seedlings of either species were observed in other, more open, areas of the population. The localized seed dispersal patterns we observe for $M$. pomifera and $G$. triacanthos thus appear to reflect the actual genetically effective patterns.

In the absence of selection, plant species with similar ecological characteristics should exhibit similar patterns of genetic structure within their populations (Loveless \& Hamrick, 1984). We found this to be true for $M$. pomifera and $G$. triacanthos, both of which showed the strongest spatial autocorrelation within clumps and among near neighbours, and almost no positive autocorrelation at greater distances. Although differences between the two species in the proportion of alleles that were autocorrelated were not statistically significant, there was some indication that spatial genetic structure may be developing more slowly for $M$. pomifera. $\mathrm{Li}(1976)$, in fact, has shown that the rate at which a population loses heterozygosity due to selfing and mating among relatives is much slower for autotetraploids than for diploids, which would inhibit the development of spatial genetic structure as a result of limited gene flow. We plan to investigate this question more thoroughly in the future through the use of computer simulations.

\section{Acknowledgements}

This work was funded by NSF Doctoral Dissertation Improvement grant BSR-851447 to JLH for AS, a University of Kansas General Research grant to JLH, and a grant from Sigma Xi, The Scientific Research Society to RHL. John Heywood kindly supplied the computer program for autocorrelation analyses. We also thank an anonymous reviewer, who made several thoughtful suggestions for improving the manuscript.

\section{References}

BAYER, R. I. 1989. Patterns of isozyme variation in western North American Antenneria (Asteraceae: Inuleae) II. Diploid and polyploid species of section Alpinae. Am. J. Bot, 76, 679-691.

BUGBEE, R. E. AND RIEGEL, A. 1945. Seasonal food choices of the fox squirrel in western Kansas, Kans. Acad. Sci. Trans., 48, 199-203.

DEWEY, S. E. AND HEYWOOD, J. s, 1988. Spatial genetic structure in a population of Psychotria nervosa. I. Distribution of genotypes. Evolution, 42, 834-838.

DICE, L. R. 1945. Some winter foods of the cottontail in southern Michigan. J. Mammal., 26,87-88.

EPPERSON, B. K. 1990a. Spatial patterns of genetic variation within plant populations. In; Brown, A. H. D., Clegg, M. T., Kahler, A. L. and Weir, B. S. (eds) Plant Population Genetics, Breeding, and Genetic Resources, Sinauer, Sunderland, Massachusetts, pp. 229-253.

EPPERSON, B. K. 1990b. Spatial autocorrelation of genotypes under directional selection. Genetics, 124, 757-771.

EPPERSON, B. K. AND CLEGG, M. T. 1986. Spatial-autocorrelation analysis of flower color polymorphisms within substructured populations of morning glory (Ipomoea purpurea, Am. Nat., 128, 840-858.

FOWELLS, H. A. 1965. Silvics of Forest Trees of the United States. Agriculture Handbook No. 271. US Department of Agriculture, Washington, DC. 
FRIEDMAN, S. T. AND ADAMS, W. T. 1985. Estimation of gene flow into two seed orchards of loblolly pine (Pinus taeda L.). Theor. Appl. Genet., 69, 609-615.

GABRIEL, K. R. AND SOKAL, R. R. 1969, A new statistical approach to geographic variation analysis. Syst. Zool., 18, $259-278$.

GORDON, D. 1966. A revision of the genus Gleditsia (Leguminosae). Ph.D Thesis, Indiana University, ChampagneUrbana.

HALDANE, J. B. S. 1930 . Theoretical genetics of autopolyploids. J. Genet., 22, 359-372.

HAMRCK, 3. L. AND GODT, M. J. W. 1990. Allozyme diversity in plant species. In: Brown, A. H. D., Clegg, M. T., Kahler, A. L. and Weir, B. S. (eds) Plant Population Genetics, Breeding, and Genetic Resources, Sinauer, Sunderland, Massachusetts, pp. 44-64.

HAMRICK, J. L, AND HOLDEN, L. R. 1979. Influence of microhabitat heterogeneity on gene fJequency distribution and gametic phase disequilibrium in Avena barbata. Evolution, 33, $521-533$.

HAMRICK, J. L., LJNHART, צ. B. AND MITTON, J, B. 1979, Relationships between life history characteristics and electrophoretically detectable genetic variation in plants. Ann. Rev. Ecol. Syst, 10, 173-200.

HARJU, A. AND MUONA, O. 1989. Background pollination in Pinus sylvestris seed orchards. Scand. J. For. Res., 4, $513-520$.

JAIN, S. K. AND BRADSHAW, A. D. 1966. Evolutionary divergence among adjacent plant populations. I. Evidence and its theoretical analysis. Heredity, 21, 407-441.

LAUSHMAN, R. H., SCHNABEL, A. AND HAMRICK, J. L. 1990. Electrophoretic evidence for tetrasomic inheritance in the dioecious tree Maclura pomifera (Raf.) Schneid. Am. J. Bot, 77, 75 (abstract).

LEVIN, D. A. 1983. Polyploidy and novelty in flowering plants. Am. Nat., 122, 1-25.

LI, c. c. 1976. First Course in Population Genetics. Boxwood Press, Pacific Grove, California.

LI, C. C. AND HORVTZ, D. G. 1953. Some methods of estimating the inbreeding coefficient. Am. J. Hum. Genet., 5, $107-117$.

LOVELESS, M. D. AND HAMRICK, J. L. 1984. Ecological determinants of genetic structure in plant populations. Ann. Rev. Ecol. Syst., 15, 65-95.

MATHWG, J. E. 1971. Relationships betwween bruchid beetles (Amblycerus robinae) and honey locust trees (Gleditsia triacanthos). Ph.D Thesis, University of Kansas, Lawrence.

MITTON, J. B., LINHART, Y. B., HAMRICK, J. L. AND BECKMAN, J. S. 1977. Observations on the genetic structure and mating system of ponderosa pine in the Colorado front range. Theor, Appl. Gentet, 51, 5-13.

NAGASAKA, k. AND SZMIOT, A. e. 1985. Multilocus analysis of external pollen contamination of a Scots pine (Pinus sylvestris L.) seed orchard. In; Gregorius, H.-R. (ed.)
Population Genetics in Forestry, Springer-Verlag, Berlin, pp. 134-138.

NESS, B. D., SOLTIS, D. E. AND SOLTIS, P. S. 1989. Autopolyploidy in Heuchera micrantha (Saxifragaceae). Am. J. Bot., 76, 614-626.

ODEN, N. L. 1984. Assessing the significance of a spatial correlogram. Geographical Analysis, 16, 1-16.

PEATTJE, D. C. 1953. A Natural History of Westem Trees. Houghton Mifflin, Boston, Massachusetts.

ROHLF, F. J. AND SCHNELL, G. D. 1971. An investigation of the isolation by distance model. Am. Nat., 105, 295-324.

SCHNABEL, A. 1988. Genetic structure and gene flow in Gleditsia triacanthos L. Ph.D Thesis, University of Kansas, Lawrence.

SCHNABEL, A. AND HAMRICK, J. L. 1990. Organization of genetic diversity within and among populations of Gleditsia triacanthos (Leguminosae). Am. J. Bot., 77, 1060-1069.

SCHOEN, D. J. AND LATTA, R. G. 1989. Spatial autocorrelation of genotypes in populations of Impatiens pallida and Impatiens capensis. Heredity, 63, 181-189.

SMITH, J. L. AND PERINo, J. V. 1981. Osage orange (Maclura pomifera): History and economic uses. Econ. Bot., 35, $24-41$.

SOKAL, R. R. AND ODEN, N. L. 1978. Spatial autocorrelation in biology 1. Methodology. Biol. J. Linn. Soc., 10, 199-228.

SOKAL, R. R., JACQUEZ, G. M. AND WOOTEN, M. C. 1989. Spatial autocorrelation analysis of migration and selection. Genetics, 121, 845-855.

SOLTIS, D. E. AND SOLTIS. P. S. 1989. Genetic consequences of autopolyploidy in Tolmiea (Saxifragaceae). Evolution, 43, 586-594.

SOLTIS, D. E., HAUFLER, C. H., DARROW, D. C. AND GASTONY, G. J. 1983. Starch gel electrophoresis of ferns: a compilation of grinding buffers, gel and electrode buffers, and staining schedules. Am. Fern. J., 73, 9-27.

STEBBiNs, G. L. 1980 . Polyploidy in plants: unresolved problems and prospects. In: Lewis, W. H. (ed.) Polyploidy, Plenum, New York, pp. 495-520.

TURKINGTON, R. AND HARPER, J. L. 1979. The growth, distribution, and neighbour relationships of Trifolium repens in a permanent pasture. IV. Fine scale biotic differentiation. $J$. Ecol., 67, 245-254,

TURNER, M. E., STEPHENS, J. C. AND ANDERSON, W. W. 1982. Homozygosity and patch structure in plant populations as a result of nearest-neighbor pollination. Proc. Natl. Acad. Sci, USA, 79, 203-207.

WOLF, P. G., solt7s, D. E. AND Soltis, P. S. 1990. Chloroplast-DNA and allozymic variation in diploid and autotetraploid Heuchera grossulariifolia (Saxifragaceae). Am. J. Bot., 77, 232-244.

WRIGHT, S. 1943. Isolation by distance. Genetics, 28, 114-138.

ZAR, t, H. 1974. Biostatistical Analysis. Prentice-Hall, Englewood Cliffs, N.J. 